LBI $-\mathbf{2 1 9 3 1}$

DE87 003635

\title{
Pressure Regulation System for Modern Gas-filled Detectors*
}

\author{
R.J. McDonald \\ Accelerator and Fusion Research Division \\ Lawrence Berkeley Laboratory \\ University of Califomia \\ Berkeley, CA. 94720
}

\begin{abstract}
A gas pressure and flow regulation system has been designed and constructed to service a wide variety of gas-filled detectors which operate at pressures of 2-1000 Torr and flow rates of $\sim 5-200$ standard cubic centimeters per minute (sccm). Pressure regulation is done at the detector input by a pressure transducer linked to a solenoid leak valve via an electronic control system. Gas flow is controlled via a mechanical leak valve at the detector output. Interchangeable transducers, flowmeters, and leak valves allow for different pressure and tlow ranges. The differential pressure transducer and control system provide automatic let-up of vacuum chambers to atmospheric pressure while maintaining a controlled over-pressure in the detector. The gas system is constructed on a standard 19" rack-mounted panel from commercially available parts. Five of these systems have been built and are routinely used for both ionization chambers and position-sensitive avalanche detectors.
\end{abstract}

"This work was supported by the Director, Office of Energy Research, Office of High Energy and Nuclear Physics, Nuclear Science Division, U.S. Department of Energy under Contract \#DE-ACO3-76SF00098 


\section{Introduction:}

Gas-filled radiation and particle detectors ${ }^{1}$ have played an important role in nuclear and atomic physics from the earliest Geiger counters and proportional chambers to the most recent position-sensitive avalanche detectors, ionization chambers, driff chambers, multi-wire proportional chambers, Bragg-curve spectrometers, and time projection chambers. Although solid state and various other types of liquid and solid detectors have replaced gas-filled detectors for most applications involving the detection of photons and light charged particles, gas-filled deteclors have become increasingly used for heavy-ion research ${ }^{2}$ because of their flexibility and radiation-damage resistance. Large solid-angle position-sensitive ionization chambers (ICs) ${ }^{3}$ can be made to incorporate thin $\triangle E$ detectors as $w$ \| as full-energy stopping detectors for heavy lons into the tens of $\mathrm{MeV} /$ nucleon energy range. Pos 'ion-sensitive avalanche deleclors (PSADs) 4.5, while not suitable for $\triangle E$ or $E$ measurements, have excellent position and timing characleristics. They are typically used in applications where position a d time-ef-flight information provide the velocities of the reaction producls. In all cases, gas-filled detectors are impervlous to radiation damage in contrast to solid-state detectors which can be rapidly damaged by heavy ions, with the damage rate increasing as a function of the ion mass. Central to the successful use of gas-filled counters is a reliable gas pressure and flow regulation system that is capable of maintaining pressure regulation to better than $\pm 1 \%$. In the past, various mechanical pressure control devices have been used; for example the "Cartesian Diver" manostat ${ }^{6}$ or simply two needle valves with a detector in s- jies between them. Not only did these mechanical systems provide relatively poor regulation, but they required long times to stabilize and were subject to operator errors that could result in the destruction of delicate detector windows. Modern transducer and control technology now exists to construct gas pressure and flow regulation systems that do not have these limitations.

\section{Design Considerations:}

To understand the design of this gas system, one must understand the basics of the two main types of detectors it was specifically designed for and the environment in which these detectors are used. Heavy-ion nuclear reactions are typically performed in high vacuum ( $<10^{-5}$ Torr ) chambers because many of the reaction fragments have relatively short ranges in matter. Thus, the detector windows must be as thin as possible, yet they may have to hold substantial pressures of gas. ICs are typically operated at pressures of 50-500 Torr and have relatively strong windows. PSADs are typically operated at 2-10 Torr and have very delicate windows. Thus, the gas regulation system must have a large dynamic range in

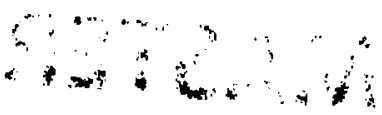


This bouk was prepared as an account of work sponsired by an agency of the United States Government. Neither the United States Covern ment nor any agency thereof, nor any of thes employees, makes any warranty, expreas or '.,plied, or assumes any legal liability or responsibility for the accuracy, completeness, or usefulness of any information, apparatus, product, or process disclused, or represents that its use would not infringe privalely owned rights. Reference herein to any specific commercial product, process, or service by trade name, trademark, manufacturer. or otherwise, does not necessarily constitute or imply its endorsement, recommendation, or fovor. ing by the United States Covernment or any agency thereol. The views and opinions of authors expressed herein do not necessariby state or reflect those of the United States Covernment or any agency thereot. 
pressure and be capable of protecting delicale windows from fatal over pressure.

The primary consideration in designing a gas pressure and flow regulation system is the ability to maintain a stable pressure in the detector for the duration of the experiment, normally several days. Of equal importance is the response of the system to transients in pressure, providing some built-in protection for detectors with delicate windows. The system should also be easy to operate 50 as not to encourage operator error. These criteria are fulfilled in the following design:

Pressure stability is obtained by using a closed-loop control circuit in which a reservoir before the detector is maintained at constant pressure by a solenoid leak valve, pressure transducer and controller, and flow is controlled by a manually-operated needle valve following the detector. The transducer and solenoid leak valve are located as close as possible to the reservoir to reduce the feedback time constant of the system. A flowmeter, located on the high pressure side of the solenoid leak valve, measures gas flow. During the sieady-state operation of the system, the transducer monitors the pressure difference between the reference (usually a chamber at high vacuum) and the input reservoir, and compares its reading to the set-point on the controller. The difference is a error signal which is amplifled and shaped to become the signal to control the solenoid leak valve. This particular system utilizes the MKS Instruments Inc. model 223B transducer, the model 248A leak valve, and and the model 250B pressure / flow controller to regulate pressure. The specifications of this control system suggest an accuracy of $0.25 \%$ of full scale. No attempt was made to compensate for temperature changes, since this requires the transducer to be mounted near the detector and connected to a filled reference volume.

Since precision transducers and control systems covering the large dynamic range needed are not readily available, the Iransducer must be easily changed. Transducers having a full-scale range of 10 Torr, $100 \mathrm{Torr}$, or 1000 Torr are readily available and may be used interchangeably. Similarly, the leak valve may be changed to accommodate different flow rates. Normally, either a $100 \mathrm{sccm}$ or a $200 \mathrm{sccm}$ valve is acceptable. Since these components are connected via Cajon VCO fittings, they are easily interchangeable. Welded stainless steel construction is utilized to maintain gas purity and vacuum integrity. Table 1 lists the main components of the system. This system protects delicate windows by keeping the detector at a slight over pressure during the transients of chamber pump-down and let-up via a large diameter ( $\sim 2 \mathrm{~cm}$ internal diameter) reference line connected between the gas system and the chamber. During pump down, gas flows from the detector to the gas system and back to the vacuum chamber through valve V5 and the reference line, insuring slight over pressure. During let-up, the differential transducer senses the pressure difference between the chamber and the input reservoir and adjusts the leak valve ( $\mathrm{V} 4)$ to maintain a small positive pressure differential between the detector and the chamber.

Because this system was designed io be easily accessible to outside users of our facility, a large 
amount of care was taken to insure simplicity of operation with all controls on the front panel. Figure 1 shows a picture of the front panel. Note that all valves are of the "quarter turn type" (including V5 which is a small butterfly valve) so it is clear which valves are opened or closed. Bourdon gauges are located at every important part of the system to reduce the chances of opening a critical valve without knowing the pressure on both sides of it. Thermocouple gauges are located at four points in the system and may be used to check for leaks. The actuai gas circuit is shown on the front panel. Figure 2 shows a logical schematic of the gas system. Note the near identity of the schematic and the front panel.

\section{Operational Details:}

The gas system should be set up in accord with figure 2 for the gas and vacuum connections and in accord with the MKS instructions for the electronic connections. One important addition should be some device, in our case a voltmeter, to monitor the state of openness of the solenoid valve (V4). Various other options, such as automatic shut-down in case of deviation of pressure from set limits may also be implemented.

A unique aspect of this system is its function during transients, namely chamber and detector pump-down and let-up. During pump-down, one closes both the solenoid leak valve (V4) and the exhaust valve (V9) and opens a bypass between the chamber and the gas system (V5). The detector remains at higher pressure than the chamber during chamber pump-down because of impedance in the gas lines. $A$ connection between the input and exhaust manifolds (V10) allows for the system (betore V4) and the gas input line to be purged. The input mainfold may now be filled with counter gas to a pressure slightly greater than atmospheric (1-3 PSI) as adjusted by a regulator on the gas bottle and measured on gauge G1. The transducer should be elecironically zeroed when the chamber pressure is at high vacuum ( $<10^{-3}$ Torr) and valve V5 is open. By closing valve V5, the gas system and the chamber are separated. Opening V9 activates the exhaust pump. The pressure controller set-point should now be adjusted to the desired pressure taking care to avoid transients by moving the set-point dial slowly and adjusting the gain and phase lead settings.

For let-up to air, only valve V9, the exhaust valve, need be closed; although one will norrnally also close the gas inlel valve (V1) and open the air inlet valve (V2). As one leaves air into the chamber (V 11), the pressure on the reference side of the transducer will rise causing the solenoid valve to open to maintain a higher pressure in the detector than in the chamber as determined by the controller. One may increase the flow to the chamber through V11 until the flow into the delector through $V 4$ is $\sim 80 \%$ of the 
solenoid valve capacity as measured by the flowmeter. After reaching atmospheric pressure, one closes the solenoid valve V4 and opens the bypass valve V5 10 secure the system.

Although none of the valves labeled " $O$ " for optional are necessary, at least some of them may be useful. In particular, the valve 05 should be an air activaled valve on the exhaust pump that is interlocked with the pump's AC power. In the event of power failure, the valve will close and latch off. This will keep air from back-streaming through the pump and bursting the detector window. Valve 01 is an extra bypass that provides some additional protection to the detector during pump-down. Valves 02,03 , and 04 serve 10 separate the gas system from the chamber and detector, allowing the gas system to be separaled from the chamber without breaking chamber vacuum.

\section{Summary:}

Because the proper operation of gas-filled detectors depends critically on maintaining constant pressure and the lact that some gas-filled detectors are quite delicate, a gas pressure regulation system was designed to provide constant pressures and automatic protection for the detector during the transient phases of chamber pump-down and let-up to air. Interchangeable parts allow one to operate over a wide range of pressures and flow rates to provide for the needs of different types of detectors. The construction and panel arrangement provide all the information needed to run the system so that casual users can operate it reliably. So far, five of these syslems have been constructed at two labs. They are routinely used at the three particle accelerators at Lawrence Berkeley Laboratory and have been taken to other laboratories. The cost of the gas pressure regulation system is about $\$ 6000$. Additional drawings and construction details are available from the author upon request. 


\section{References}

1. For a general discussion of gas-filled detectors, see: Glen F. Knoll: Radiation Detection and Measurement. John Wiley \& Sons, New York, 1979 Section B

2. U. Lynen, H. Stelzer, A. Gobbi, H. Sahn, and A. Olmi: Large-area. Two-dimensional Position Sensitive Detectors. Nucl. Inst. and Meth. 162 (1979), 657,675

3. H. Sahn, H. Damjantschitsch, D. Hebbard, J. Junge, D. Pelte, B. Povh, D. Schwalm, and D. B. Tran Thoai: APosition-sensilive lonization Chamber. Nucl. Inst. and Meth. 124 (1975), 509-519

4. Herbert Stelzer: ALarge Area Parallel Plate Avalanche Counter. Nucl, Inst. and Methods 133(1976), 409-413

5. Y. Eyal and H. Stelzer: Iwo Dimensional Position Sensitive Transmission Parallel Plate Avalanche Counter. Nucl. Inst. and Meth. 155 (1978) 157-164

6. Roger Gilmont: Design and Operational Characteristics of Cartesian Manostats. Analytical Chemistry 23 (1951), 157-161 


\section{Figure Captions}

1. Picture of the gas regulation system including the MKS pressure / flow controller and a set of thermocouple gauge read-outs. The system is shown in a "secured" configuration, with valves V4 and V9 closed, and valve V5 open. Note the similarity between the front panel and the schematic shown in figure 2.

2. Schematic diagram of the gas regulation system. Valves $(V)$, optional valves $(O)$, Bourdon gauges $(G)$, and optional thermocouple gauges (TC) are shown. Operation is explained in the text.

\section{TABLE 1}

\section{LIST OF MAJOR COMPONENTS}

Transducer:

Leak Valve:

Controller:

Valves:

Flowmeter:

Tubing:

Manifolds:

Connections:

Bourdon gauges:
MKS Instruments, Inc. Model 223B

MKS Instruments, Inc. Model 248A

MKS Instruments, Inc. Model 250B

V5: $0.1 .9 \mathrm{~cm}$ butterfly; all others: Nupro SS-4D4L

Matheson 600 or 610 , modified to be vacuum tight

304 Stainless 0.32 internal diameter

304 Stainless $1.9 \mathrm{~cm}$ internal diameter

Cajon VCO or welds

G1: 30" vacuum to $15 \mathrm{PSI}$ compound gauge

G2-G5: 0-30" vacuum 


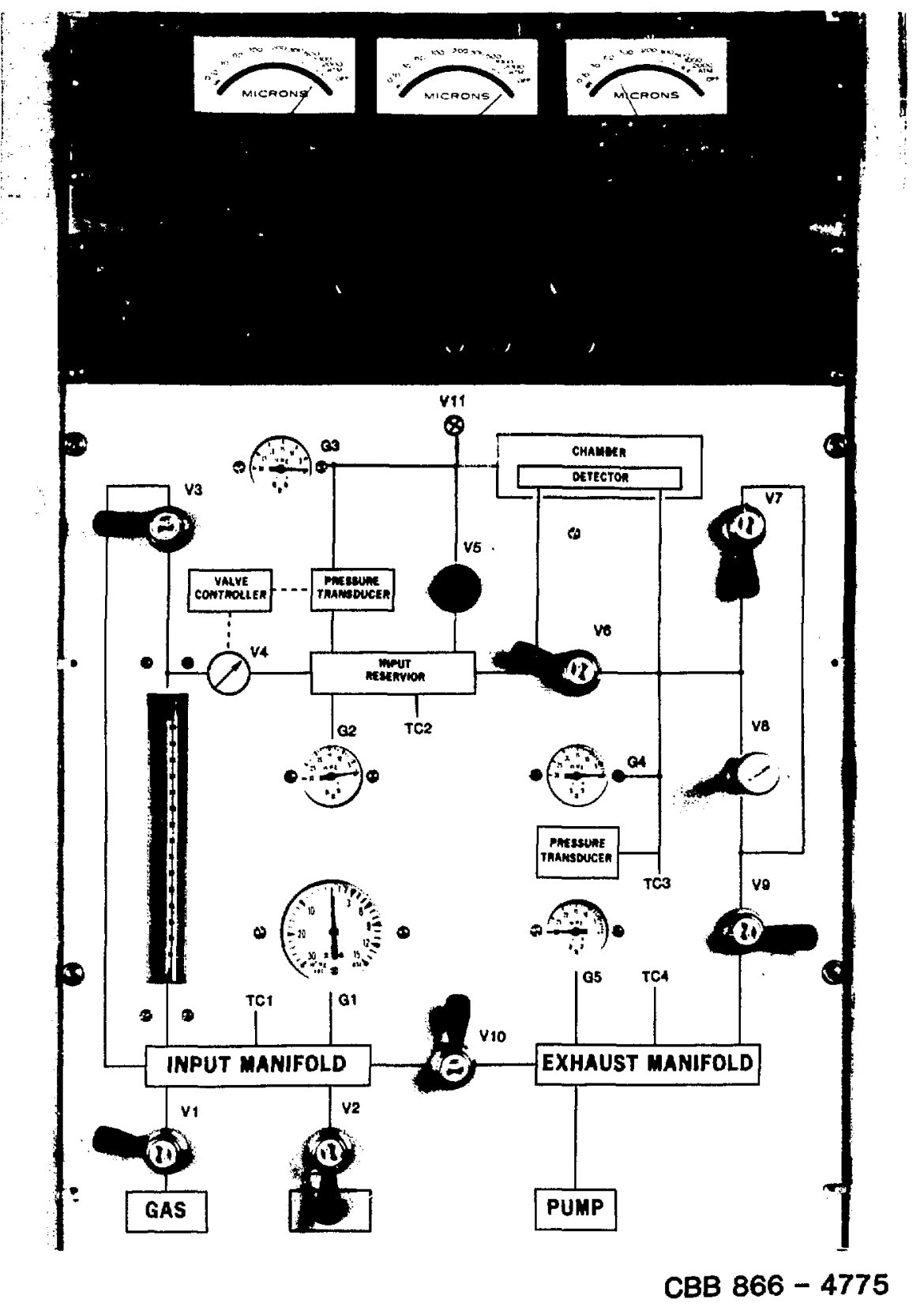

Figure 1 


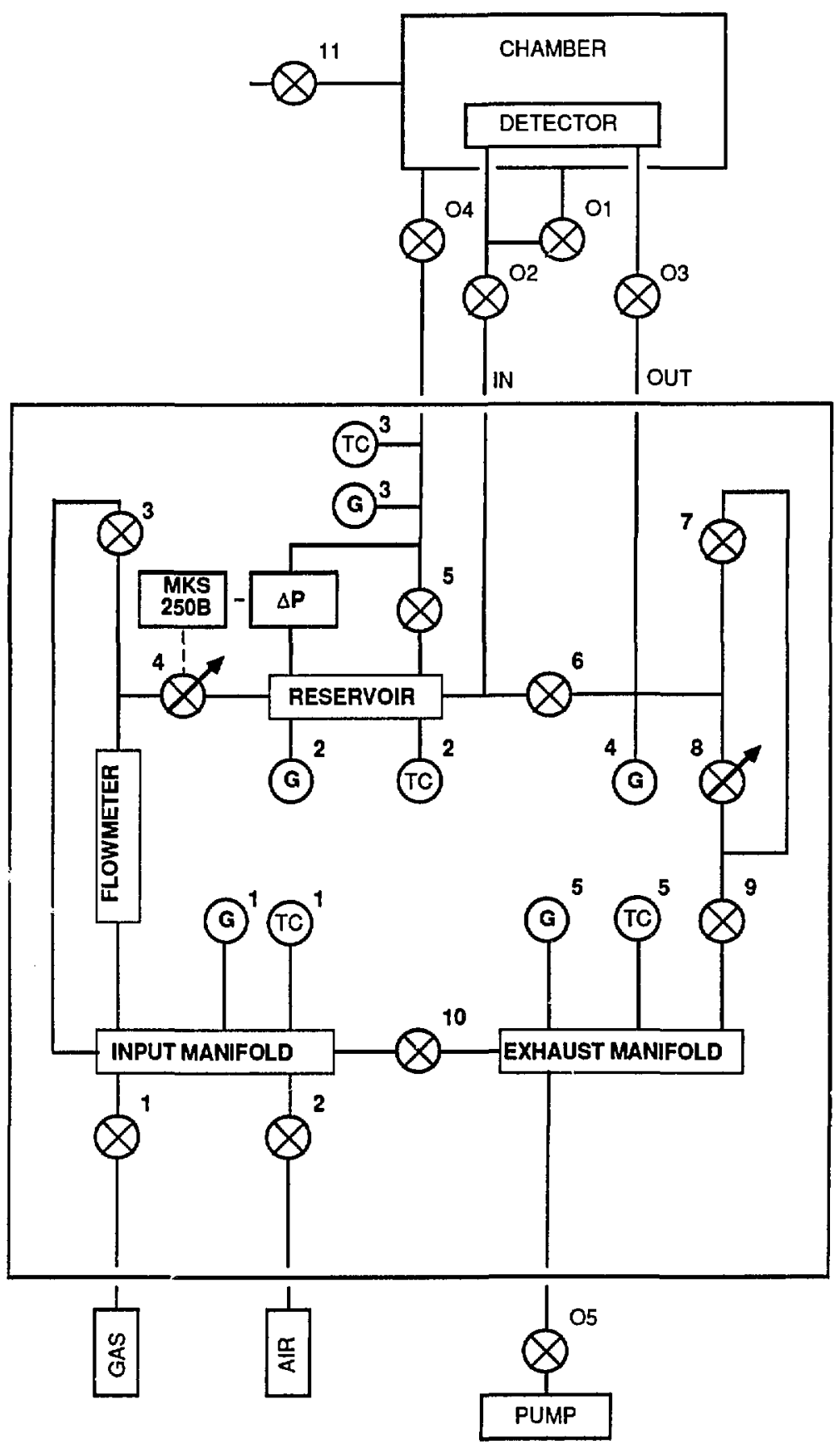

Figure 2 


\section{Appendix}

\section{Sel-up and Operating Instructions}

\section{System Set-up:}

\section{a) Choice of interchangeable components:}

There are three interchangeable componenls in the gas system: 1) The transducer, 2) the leak valve, and 3) the flowmeter. The transducer must be selected according io the pressure needed. Of the three ranges available, 10,100, and 1000 Torr, the 10 and 1000 Torr are the most useful. For pressures below

10 Torr, naturally, one wants the 10 Torr full scale transducer. For pressures between $\sim 50$ Torr and 1000 Torr, one may use the 1000 Torr transducer. The 100 Torr range is needed less often since detectors rarely run in the 10.50 Torr range. The leak valve is normally a 100 or $200 \mathrm{sccm}$ range solenoid valve. For detectors like PSADs that need very low flow rates ( $<10 \mathrm{sccm}$ ), the $100 \mathrm{sccm}$ valve is best, but the 200 $\mathrm{sccm}$ range is acceptable. For large ionization chambers, one should use the $200 \mathrm{sccm}$ model, and may even want to consider a higher flow range. Normally, the Matheson 610 flowmeter, which has a range of about $100 \mathrm{sccm}$, is adequate for all detectors, and it is particularly useful since it can measure low flow rates. The Model 600 is also acceptable. Naturally, other ranges of these components are available, and the user should consult the manufacturers' catalogues for a complete list and compare those available with his or her requirements. Interchangeable parts are connected with Cajon VCO fittings.

\section{b) Electronic Set-up:}

Before using the system, one should become familiar with the manuals for the MKS 250B pressure / flow controlier, the 223B transducer, and the 248A solenoid leak valve. The transducer and leak valve must be connected to the controller via the appropriate cables. The cable to the solenoid valve should be modified to provide atlachment of a voltmeter in parallel with the valve. The purpose of this meter is to determine how open the valve is. With the valve control on the MKS 250B in the "off" position, the meter should read 0 Volts. If the meler does not read 0 volts, the cable between the MKS $250 \mathrm{~B}$ and the valve is probably wired wrong. With the valve control in auto or manual, and the set point at zero, the valve "bias" adjust can be read. This should typically be a few volis and may be adjusted with the poientiometer on the front panel of the MKS 250B. A fully open valve should give a reading of 14 volts. 


\section{c) Exhaust Pump Set-up:}

The output side of the exhaust manifold (1" LRL fitting ) should be connected to a 15 cubic foot per minute (cfm) or larger capacity mechanical pump. It is best to install an optional air-activated shut-off valve $(O 5)$ interlocked to protect against pump failure either because of loss of power or a broken drive belt. The interlock should latch the pump off until an operator intervenes and decides it is safe to restart the pump. In case of such a failure, the bypass valve V5 should be opened to empty the detector. (Note: one should rnake sure this will not harm anything in the vacuum chamber, in particular make sure DETECTOR BIASES ARE OFF!!)

d) Reference line:

The reference line (1" LRL fitting) should be connected to the chamber eilher directly or through the optional valve 04 . The relerence line should be as short in length as possible, so the relerence pressure at the transducer is always as near as possible to the pressure in the chamber. The gas input and output should be connected to the chamber feed-throughs either directly or through the optional valves 02 and 03. The optional bypass 01 is a relic from the days of mechanical gas systems, but is still useful for some extra protection during the pump down stage only. Valve 01 must NOI be open during let-up. The use of optional valves $\mathrm{O} 2,03$, and $\mathrm{O} 4$ allow one to separate the gas system from the chamber without breaking vacuum. This is an advantage if one needs to change or remove the gas system.

\section{e) Preparation for use:}

At this time, the system should be prepared for use by making sure that all parts of the system, detector, and chamber are at atmospheric pressure and that the following condit? ins hold:

1) Optional valves $01-04$ are opened.

2) The MKS $250 B$ is tumed on.

3) The optional thermocouple gauges (ii used) are turned on.

4) Valve $V 4$ is closed via the MKS $250 \mathrm{~B}$ switcl and valve V9 is closed.

5) The mechanical exhaust pump is on and valve 05 , if used, is open. G5 should read $30^{\prime \prime}$ of vacuum.

\section{2) Operation:}

The system logically divides across the imaginary diagonal line from valve $\mathrm{V} 4$ to valve V9. When value $V_{5}$ is open, the part above this imaginary line is connected to the chamber cirectly and is lugically 


\section{a) Pump Down:}

Valves V4 and V9 must be closed and the bypass valve V5 must be open. It is helplul to have valves $V_{6}$ and $V 7$ open to improve conductance. The system above the imaginary valve $V_{4}$ to valve $V_{9}$ line and the detector are now part of the chamber and will be pumped down with it. The detector will be at a higher pressure than the chamber because of the impedance in the connecting lines between the detector and the gas system. Pump down the chamber at a rate you feel comfortable with (10-30 minutes). Gauges G2, G3, and G4 should all go to 30 " vacuum. At the end of the pump-down, one should zero the transducer and the MKS 250B according to the instructions in the manuals.

\section{b) Purge:}

Because solenoid valves are typically poor shut-off valves, one may need to start the purge of the input side of the system (belore valve V4) before the chamber reaches high vacuum ( $10^{-1}$ milli Torr ). Looking at the system below the imaginary valve $V_{4}$ to valve $V 9$ line; you may open valves $V_{10}$ and $V_{3}$ to purge the gas system. You may also open valve $V_{1}$ to purge the input line to the gas bottle. (Do not pump directly on a regulator unless it is certified for vacuum). Valve V2 must be closed. At this time gauges G1 and G5 ought to go to 30" vacuum. Valve V10 should row be closed.

\section{c) Filling:}

Open the exhaust valve VS to activate the defector exhaust pump and close the bypass valve V5 to separate the gas system from the chamber. Close valve V3 to activate the flowmeter. Fill the input manifold through valve $V_{1}$ to the desired pressure as read on gauge $G 1$ utilizing the regulator on the gas bottle. Normally this pressure should be slightly above atmosphere ( +1-3 PSI) although for some detectors running at very low pressures (i.e. 2 Torr) and low flows ( $<10 \mathrm{sccm}$ ), one may want to set the regulator for only $1 / 2$ atmosphere to begin with and raise this pressure only after a stable flow is established. The reason for running the input above atmospheric pressure is to insure that any leak in the input line does not contaminate the gas. At this time it is permissible that the pressure in the input reservoir as read on the MKS 250B controller rises slightly (<0.5 Torr / minute) indicating slight leakage through the leak valve. If this rate is faster, open valve $V 5$ to protect the system and trouble-shoot the solenoid valve for a leak. (You may try tightening the seat as discussed in the MKS 248A manual.)

With the auto set point on the $250 \mathrm{~B}$ controller at zero; switch the valve position from close to auto. A voltmeter across the valve should read a voltage proportional to the bias (2-3volts) but the pressure should not rise significantly ( $<0.5$ Torr / minute). Slowly increase the set point on the MKS $250 \mathrm{~B}$ to the 
desired pressure. Adjust the gain on the MKS $250 \mathrm{~B}$ to $\sim 75$ and the phase lead to $\sim 5$ seconds to begin with. After the system is running, you may optimize these adjustments in accord with instructions in the manual. The voltage across the valve should be 7-10 volts. Adjust the seat if necessary. Close valve V6 to direct all the flow through the detector and close valve V7 to activate the ouiput needle valve V8. Adjust the manual leak valve V8 for the required flow. (Note: for some very low pressure systems, i.e. 2 Torr, you may have to open the valve $V 7$ at least part way to get enough flow or to keep the pressure from rising above the set point. You may also need to adjust the valve seat on the MKS 248A as discussed in the manual to reach this condition. For detectors at high pressures ( 200-500) Torr, you may have to throttle valve V9 to keep the flow rate down. At this point you should have steady pressure and flow.

\section{d) Letting up to air:}

TURN OFF_THE DETECTOR SIASIII Close the gas input valve $V_{1}$, seal off the gas bottle, and open the air vaive $V_{2}$. You should now have the same pressure and the same flow of air as you had of gas. Lower the set point to the pressure you wish to have when you let up. ( Let up at the greater of $10 \%$ of the defector operating pressure or 1 Torr, whichever is greater.)

When the proper pressure is reached; close the exhaust valve V9. You mey also want to open valves $V_{6}$ and $V 7$ to increase conductance in that part of the gas system. Valve $V_{4}$ ought to begin to close automatically as indicated by a decreasing reading on the voltmeter in parallel with the valve. Open the up to air valve V11 on the chamber slowly. Valve V4 should begin to open again. Let in air at such a rate that the flowmeter reads $\sim 80 \%$ of full scale, making sure this does not exceed the maximum flow limit of the MKS 248A leak valve. You should not have to touch the systern again until it's up to atmospheric pressure. As it reaches equilibrium with the room; the flowmeter reading will tend toward zero, the transducer reading will also tend toward zero, and the voltage across the valve will increase to $\sim 14$ volts. When the flowmeter reads zero and the transducer reads nearly zero, you are up to air.

\section{e) Securing the System:}

Close valve V4 electrically using the switch on the MKS 250B, and return the set-point on the MKS 250B to zero. Open the bypass valve V5, and your system is now safe to leave. You may open valves $V_{6}$ and $V_{7}$ if they are not already open. Since valve $V_{9}$ is closed; you are now ready to pump down again if you want to. You may turn off the controller if you do not expect to use the system for a while. 


\section{Checklist}

Set-up:

1) All connections are made in accord with figure 2

2) MKS electronics are on

3) All parts of the system are at atmospheric pressure

Pump-down:

1) Valve $V_{4}$ and $V 9$ are closed

2) Valves V5, V6, and V7 are open

3) Exhaust pump is on

The chamber may now be pumped down

Purge:

1) Vaives $V_{2}, V_{4}$ and $V 9$ are closed

2) Valve $V_{1}$ is open

Open valve V10 slowly to purge

Filling:

1) Valves $V_{3}, V_{5}$, and $V 10$ are closed

2) Valve $V g$ is opened

Fill input manifold and set regulator for $\sim 1-3 \mathrm{PSI}$

Running:

1) Set V4 control to "Auto"

2) Set Gain to $\sim 75$ and phase lead to $\sim 5$ seconds

Set pressure on the MKS 250B controller

Up-to-air:
1) TURN OFF DETECTOR BIAS
2) Valve $V_{1}$ is closed and valve $V 2$ is opened
3) Set pressure ior let-up to air
4) Close valve V9

Let air into the chamber through valve $V_{11}$

Securing: $\quad$ 1) Close valve V4; return set-point to 0

2) Valves V5, V6, and V7 are opened

3) Gas bottle is turned off 
This report was done.with suppor from the Department of Enersy. Any conclusions or opinions expressed in this report represent solely those of the author(s) and not necessarily those of The Regents of the University of California, the Lewrence Berkeley Laboratory or the Department of Energy.

Reference to a company or product name does not imply approval or recommendation of the produce by the University of California or the U.S. Department of Energy to the exclusion of others that may be suitable. 